\title{
Blended Learning Mobility Approach and English Language Learning
}

\author{
Mazen Ismaeel Ghareb', Saman Ali Mohammed² \\ ${ }^{1}$ Department of Computer Science, College of Science and Technology, University of Human Development, Sulaymaniyah, \\ Iraq, ${ }^{2}$ Department of English, College of Languages, University of Human Development, Sulaymaniyah, Iraq
}

\section{A B S T R A C T}

Although the benefits of blended learning have been well documented in educational research, relatively few studies have examined blended mobilities in education in Kurdistan region government and in Iraq. This study discusses a blended mobility approach for a teacher training program designed for in-service English language teachers (ELT) and investigates its effectiveness by comparing the latest participation of the University of Human Development for computer science and proposing the same program for training English for lecturers and students. The research involved proposes new mobility program for teaching and learning English language and using their language skills in an ongoing business project using several software for communication and management of their projects. Results will show the framework for new blended learning and blended mobilities of many different English language teaching (ELT) aspects.

Index Terms: Blended Aim, Blended Learning, Blended Mobility, Language Learning Strategies, E-Learning, Virtual Mobility

\section{INTRODUCTION}

The significance of student mobility and interuniversity exchange programs is incomprehensibly expanding, and the issue at present involves a huge spot in the motivation of instructive arrangement creators and advanced education establishments. In 2007, Erasmus program commended its $20^{\text {th }}$ anniversary. The Erasmus program is presumably one of the best-known activities of the European Commission, empowering students just as staff versatility, and intending to improve the quality and to fortify the European component of advanced education. University of Human Development participated with Erasmus as an associative partner in Erasmus program to help students and staff

\section{Access this article online}

DOI: 10.21928/uhdjst.v3n2y2019.pp1-9

E-ISSN: 2521-4217

P-ISSN: 2521-4209

Copyright (C) 2019 Ghareb and Mohammed. This is an open access article distributed under the Creative Commons Attribution NonCommercial No Derivatives License 4.0 (CC BY-NC-ND 4.0) receive more practical mobility experience to accomplish specific tasks related to their profession [1]. Mobility in space, land portability, "genuine" mobility, and physical mobility are for the most part terms used to allude to students and instructors in advanced education, "physically" moving to another establishment inside or outside their very own nation to study or instruct temporarily. In the accompanying passages, distinctive perspectives or kinds of mobility, for example, level and vertical mobility, free-mover and program portability are recognized and probably the most well-known programs are quickly depicted. The majority of the variations of geological mobility exhibited are types of physical mobility. Students' mobility can be arranged by the length of the investigation time frame abroad. When students just spend some portion of their examination program abroad or at an alternate institution in a similar nation, and just total a few modules or courses, however not entire degrees, it is alluded as flat portability (likewise called transitory, credit or non-degree mobility). Most national and European mobility programs advance this variation of portability. The greatest mobility timeframe for students and graduates in such projects is normally 1 year. With the usage of the Bologna

Corresponding author's e-mail: Mazen Ismaeel Ghareb, Department of Computer Science, College of Science and Technology, University of Human Development, Sulaymaniyah, Iraq. E-mail: Mazen.ismaeel@uhd.edu.iq

Received: 06-03-2019

Accepted: 13-04-2019

Published: 20-06-2019 
procedure and the expanding presentation of the lone ranger and Ace projects in Europe, numerous higher instruction foundations are likewise expecting an expansion in what is known as vertical mobility (additionally called degree or confirmation mobility). Here, students think about abroad for a full degree, accomplishing, for instance, their first degree at an organization in one nation (for the most part their nation of origin) and their second degree at another foundation, either in their nation of origin or abroad (for example a 4-year certification at home-Ace degree abroad). The EU Erasmus Mundus program, for instance, underpins vertical mobility in a methodical way [2]. Another meaning of Blended mobility is a term used to depict an instructive idea that consolidates physical scholastic mobility, virtual mobility, and mixed learning. It is expected to advance employability of advanced education understudies. Since 2009, it has advanced from virtual mobility, keeping the worldwide estimation of scholastic versatility, and yet giving a solid response to conceivable family related, monetary, mental and social hindrances of physical mobility [3], [4].

The virtual mobility part of mixed mobility is, for the most part, upheld using data and correspondence innovations (for example, Skype, Adobe Connect, Slack, Google Hangout, and Trello) to remain associated with the educators or potentially understudies who might be arranged at numerous far off areas. The physical mobility part is ordinarily of momentary length, extending from 2 to 14 days. There may exist numerous times of momentary portability. Brief times of physical mobility empower members to the center for several days, just on the genuine undertaking, which is troublesome in everyday life in a nearby domain [5].

Early uses of a mixed mobility configuration can be found back in 2009. Through this venture a domain was made which energizes the advancement of understudies' delicate aptitudes, for example, cooperation and correspondence, in a universal setting by methods for an inventive guidance worldview to improve such abilities without costly and broad curricular changes [6].

\section{LITERATURE REVIEW}

\subsection{Blended Learning}

Blended learning has turned into a trendy expression in numerous instructive conditions as of late, generally alluding to courses that utilize a blend of eye to eye and web-based learning [7]. The term started in work environment learning and writing but, on the other hand, is presently broadly utilized in advanced education, regularly portraying courses that have had an online segment added to them [8]. Some consideration has been paid to the utilization of blended learning in language educating overall [9]-[11]; however, next to no work has been done explicitly in English Language Teaching (ELT) settings. In fact, with reference to ELT [12], features are needed for further research to be directed into what makes a powerful blend.

Fig. 1 explains some components of blended learning.

Joining the upsides of e-learning and conventional learning situations has prompted another learning condition regularly alluded to as "blended learning," which unites customary physical classes with components of virtual learning [13]-[15]. One of the fundamental ideas hidden in this methodology is that:

The individuals who utilize mixed methodologies base their instructional method on the suspicion that there are inborn advantages in face-to-face interactive (both among students and between student and teacher) just as the understanding that there are some inherent advantages in utilizing the web strategies in the learning process. Consequently, the point of those utilizing blended learning approaches is to locate an agreeable harmony between online access to learning and face-to-face human interaction [16], [17]. In a survey of research on mixed learning [18], numerous examinations were recognized that uncovered positive impacts of mixed learning on (1) students performance [19]; (2) student interest and inspiration [20]; (3) expanded access and adaptability [21], (4) cost-viability [22]; and (5) progressively dynamic and deeper learning in examination with conventional classes [23].

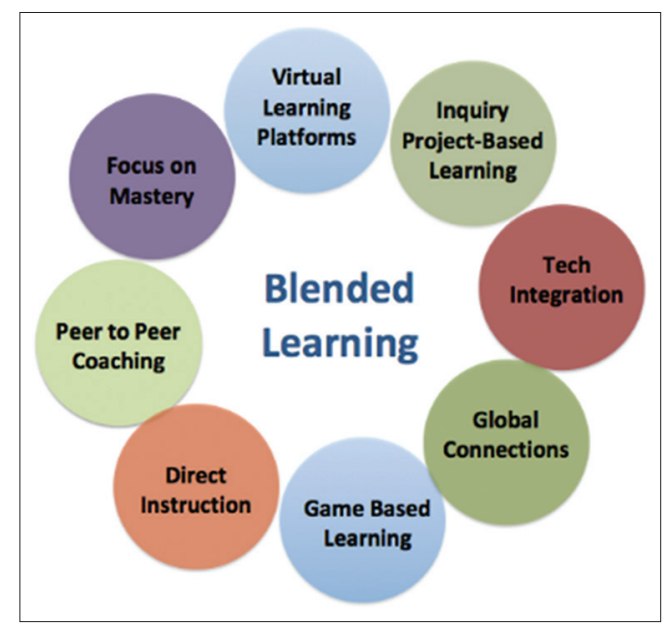

Fig. 1. Blended Learning Components 
While trying to exploit blended learning, colleges have started advertising courses joining customary up close and personal instructional components with internet learning segments [24] in different scholarly fields, for example, the board [25] and business [26]. Nonetheless, little research has been done on mixed learning in educator instruction explicitly [27], and distributed work has concentrated for the most part on understudies assessments and the mechanical applications presented [28]. Be that as it may, mixed learning may be able to possibly improve instructor instruction regarding both availability and quality. Blended learning has turned out to stand out amongst the most well-known approaches to educate English as a Foreign Language (EFL) due to its twofold segment, which coordinates vis-à-vis classes with virtual learning so as to offer students a wide scope of materials and assets sorted out methodologically. Thinking about the past viewpoints, in numerous instructive settings BL is a device accessible to students with the end goal for them to go past the homeroom and work on various intelligent exercises as an expansion of the immediate educating classes. Through all the mechanical assets they have around them, students can find out about various subjects and societies, surf the web and use the technological device they access, for example, iPods, ipads, PCs, Mp3s and Mp4s, among others. Notwithstanding, students are attacked by a lot of data from various sources. In this way, they get confounded and do not have the foggiest idea what to see first, which obstructs the proper utilization of the virtual material that may add to their English learning process. Along these lines, EFL instructors have the test of arranging virtual learning conditions that are engaging their students. This will enable them "to arrange" their EFL learning procedure and supplement up close and personal classes or the different way can utilize the virtual stage self-governing to get readied for the eye to eye classes. Along these lines, FL instructors are responsible for the methodological arranging of mixed courses which could be utilized to engage the EFL students. In spite of the fact that there are a few models with which to sort out a Mixed Course, we consider the accompanying model recommended by Khan [29], as shown in Fig. 2.

The institutional perspective is the primary component educators need to consider since it relies on the institutional strategies about the educational modules, the design of the material, and the organization and money related zone.

The second segment, the mechanical one, is the fundamental thought when educators plan both the disconnected and online exercises. Educators need a wide scope of mechanical assets so as to pull in their students' consideration: If the

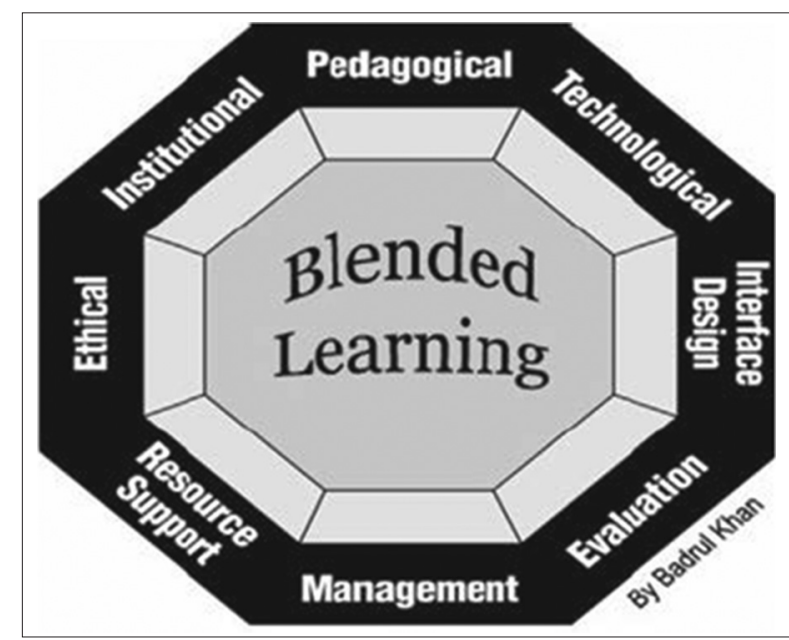

Fig. 2. Blended learning model.

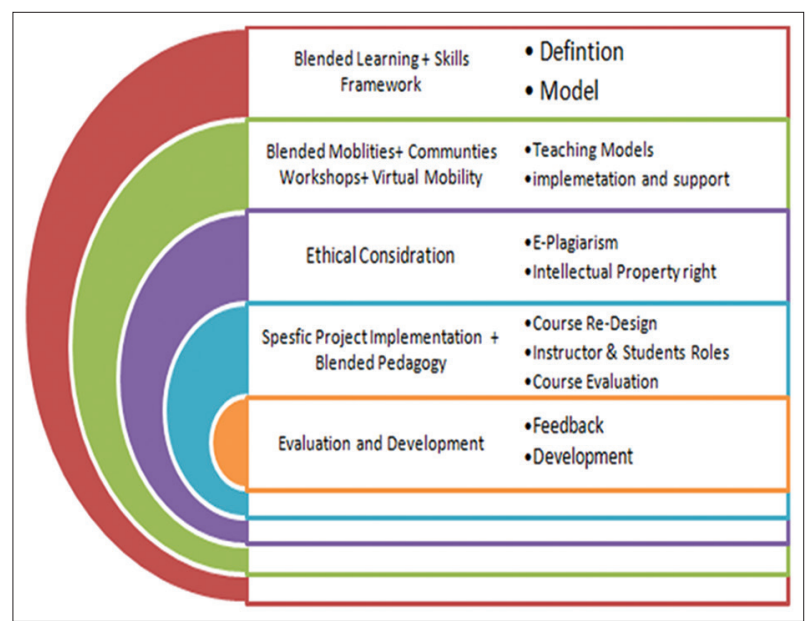

Fig. 3. Blended mobility framework.

face-to-face classes and the virtual ones are not testing, students may feel exhausted or baffled. It is important to show points and activities which are engaging them.

The third factor to hold up under as a primary concern is a pedagogical segment, which no uncertainty is the most critical one in these cross breed courses. In the event that instructors have a methodological arrangement to sort out both their up close and personal classes and the online viewpoint, it will lead the language students to prevail in their learning procedure and acquire better outcomes since they appropriately compose the two segments.

\subsection{Students Mobilities}

In last century in Europe, mobility of students, educators, and staff has been a be noticeable among the most universities and education system. As the colleges of Europe changed 
to better approaches for working in the previous decades, they have kept on supporting this profitable convention. Student mobility can be characterized by the length of the examination time frame abroad. When students just spend some portion of their investigation program abroad or at an alternate foundation in a similar nation, and just total a few modules or courses, however not entire degrees, it is alluded to as level mobility (additionally called brief, credit, or non-degree versatility). Most national and European mobility programs advance this variation of mobility. The most extreme mobility time frame for students and graduates in such projects is typically 1 year.

With the implementation of the Bologna process and the expanding presentation of Single guy and Ace projects in Europe, numerous higher instruction foundations are likewise expecting an expansion in what is known as vertical mobility (additionally called degree or certificate portability). Here, students ponder abroad for a full degree, accomplishing, for instance, their first degree at an establishment in one nation (generally their nation of origin) and their second degree at another foundation, either in their nation of origin or abroad (e.g., Bachelor certificate at home - Ace degree abroad). The EU Erasmus Mundus program, for instance, bolsters vertical portability in a methodical way [30].

Mobility can likewise be characterized by the method of association of the examination time frame abroad. Program understudies are portable students partaking in a sorted out mobility program. "Free-movers" then again do not profit by any sort of students among foundations and do not partake in a composed mobility program. "Free-mover" versatility is the most seasoned type of scholastic portability. Since the center of the 1970s composed mobility has increased expanding significance, with the ascent of organized national limited time programs (see for instance the DAAD grants) and European portability programmes. Organized or program mobility is, these days, viewed as the real mobility engine for students, graduates, doctoral hopefuls and showing staff in Europe (for example Erasmus, Leonardo, Marie Curie) and, progressively, the whole world (for example Erasmus Mundus) [30]. The topographical mobility of free-movers can occur inside a nation or crosswise over national fringes. Free-mover mobility can likewise be seen on an overall scale and is commonly not restricted to specific areas or target Nations. Interestingly, program mobility ordinarily centers on specific areas (for example, Ceepus, Nordplus...) or on specific mainlands (for example, Europe on account of Erasmus, Marie Curie) [30]. The significance and prominence of specific versatility plots frequently vary among nations and in certain nations free-mover mobility still assumes an extensive job.

Aside from the free-mover mobility and the universal participation facilitated by explicit remotely supported projects, numerous higher instruction organizations participate with one another on a reciprocal basis. Bilateral understandings between foundations are sorted out so as to fire up joint activities or increase existing contacts, and more often than not additionally make open doors for understudy and staff versatility. The upsides of such respective concurrences as to portability are for instance simplicity of utilization, smooth credit exchange, and acknowledgment of studies. Two-sided understandings can exist both on the dimension of the organization and the dimension of resources or divisions. At last, mobility can likewise be upheld in the structure of systems of advanced education foundations or understudy systems. The Coimbra Gathering Understudy Trade System for instance is a mobility plot supplementing the conventional Erasmus Mobility.

\section{BLENDED MOBILITY PROPOSED FRAMEWORK}

\subsection{University of Human Development 3.1.1. Blended}

Aim is one of those international projects that is supported and funded by the European Union in the context of scientific exchange hosted by European universities. The projects are dedicated to fourth-grade students. From each university, two students and one supervising teacher participate. The participants, both the students and the supervisor, meet twice a year in one of the member universities to present any advancement in their project and plan for future projects. The students work virtually to finish the project. The students get ECTS for their works according to their university's instructions.

We suggest that the University of Human Development get intensively involved in this unique opportunity by fitting in our university in this project as it gets bigger and bigger, and it could require enlarging our team.

\subsubsection{Calling in other colleges}

University of Human Development is participating in the blended aim project for 2018-2019 with other colleges regarding the Erasmus project calling.

\subsection{Virtual Mobilities}

With the developing noteworthiness of distance learning and e-learning, virtual mobility has turned out to be progressively 
critical in the course of the most recent couple of years. It is since the second $50 \%$ of the 1990 s that the idea of virtual mobility has picked up many with regard to the internationalization of advanced education foundations. Be that as it may, what is comprehended by virtual portability?

The elearningeuropa.info entry characterizes it as: "The utilization of data and correspondence innovations (ICT) to get indistinguishable advantages from one would have with physical mobility yet without the need to travel"[20].

This definition obviously demonstrates the two distinct components of virtual mobility. Virtual mobility is typically compared to the virtual mobility of "academic plagiarism" and adds to the internationalization of training by empowering (cross-border) collaboration between various instruction establishments. Besides, it is connected to the new conceivable outcomes opened using data and correspondence innovation (ICT) bolstered situations that incorporate, for instance, video conferencing, live spilling, community-oriented workspaces, and computer-mediated conferencing.

In the system of the Being Portable task, components, for example, the improvement of (inter-) social comprehension were added to the

definition to feature the wealth of the experience and the likenesses with the Erasmus trade program: "Virtual portability is a type of realizing which comprises virtual parts through a completely ICT bolstered learning condition that incorporates cross-border coordinated effort with individuals from various foundations and societies working and contemplating together, having, as its fundamental reason, the upgrade of intercultural understanding and the trading of information" [31], [32].

The typology is, for the most part in light of the kind of movement and the conditions in which the virtual mobility movement happens:

- A virtual course or workshop (arrangement): Students in an advanced education foundation participate in virtual mobility for a solitary course (as a component of an entire investigation program) or a course (arrangement) and the remainder of their learning exercises happen face-to-face generally;

- A virtual report program: A whole virtual investigation program is offered at one advanced education establishment, giving understudies from distinctive nations the opportunity to take this investigation program without traveling to another country for an entire scholastic year;

- A virtual mobility position: Student's situations are sorted out between a higher education foundation and an organization (now and again in an alternate nation). In the virtual mobility students use ICT to bolster their temporary position, giving them a real-life involvement in a corporate setting without the need to move from the grounds to the organization or to move to another nation for a specific period of time, and giving them a down to earth planning for new methods for working through (global) synergistic cooperation;

- Virtual help exercises to physical trade: Virtual mobility empowers both better planning and follow-up of students who take an interest in physical trade programs. Preliminary exercises could incorporate understudy determination at a separation through video- or web conferencing (for checking social and language aptitudes), furthermore, online language and social combination courses. Follow-up exercises will assist students with keeping in contact with their companions, dispersed the world over, to complete their normal research work as well as desk work. They could likewise appear as a so-called "Virtual Alumni" association, foster lifelong friendships, and networks.

In spite of the fact that the term "virtual mobility" is generally new, the European Commission has effectively advanced virtual mobility in the previous years, for the most part through the money related help of ventures inside the Socrates/Minerva and the e-learning and deep-rooted learning projects.

A portion of the later tasks managing the subject incorporate the above-mentioned Being Versatile undertaking, REVE (Genuine Virtual Erasmus), EMOVE (An operational origination of virtual portability), and More VM (Prepared for Virtual mobility), each focusing on various parts of virtual portability for various gatherings of members [3], [33].

\subsection{Blended Mobility}

While much of the time, virtual mobility speaks to an important elective answer for physical mobility, there is by all accounts general understanding that its anything but a substitute for physical mobility. Virtual mobility is, then again, ending up progressively well-known as help and supplement to conventional genuine mobility programs. It can offer extra arrangements and is an approach to additionally improve the current conventional projects, for example, Erasmus. At the point when parts of physical and virtual mobility 
are consolidated so as to boost the benefits of both, it is characterized as "blended mobility" or - whenever connected to the EU Erasmus program - "blended Erasmus."

This blended methodology is in accordance with the consequences of, for instance, the Eureca Venture, completed by the European understudy affiliation AEGEE, which suggests in addition to other things that "Erasmus understudies could be arranged as of now at their home colleges in 'active workshops' from one viewpoint, yet could likewise 'trade encounters' consequently classes" then again. The report additionally expresses that "each understudy ought to reserve the option to go to a language course that empowers him/her to pursue the scholastic program" at the host college and that "short-term trades and virtual trades could be developments." In addition, the report of the workshop on "bologna and the difficulties of e-learning and separation instruction" [34] places uncommon accentuation on the strong capacity virtual versatility can play for physical portability and show that "virtual versatility must be utilized to enhance and bolster physical versatility by better setting it up, giving powerful follow-up intends to it, and offering the likelihood to remain in contact with the home foundation while abroad. It can likewise offer (in any event part of) the advantages of physical mobility for the individuals who are generally unfit to go to courses abroad" European undertakings, for example, SUMIT (supporting mobility through ICT), ESMOS (upgrading understudy mobility through online help), triumphant (virtual educational program through dependable interoperating college frameworks) and others, recommend that the European Commission has additionally recognized virtual mobility as a help instrument in physical portability as an imperative subject. (See add II for more information). In addition, the VM-BASE venture (virtual mobility when student exchanges), in which this manual displays the outcomes, intends to raise the nature of student exchange by offering virtual help to physical mobility. In VM-BASE virtual help is utilized to plan and follow-up the portable understudy, as a supplement to the current trade programs. The venture in this way bolsters instructors in training trade understudies at a separate (e-coaching).

Student exchanges can set themselves up for their stay at a host college through, among other help exercises, virtual classes between the home and host college. Preliminary language or social courses for the understudies could be given customarily at the home college or by means of ICT from the host college before they remain. Amid their stay at the host college, they could remain associated with understudies, partners, or instructors at the home college. Furthermore, on their arrival, they could broaden their stay "essentially" by staying in touch with the host college by virtual methods.

As it shows in Fig. 3 the framework of blended mobility it a combination of blended learning and mobility learning, which is added to blended learning pedagogy in general .

\section{ENGLISH LANGUAGES SKILLS AND INFORMATION AND COMMUNICATION TECHNOLOGY}

\subsection{A. Listening}

Interactive activities to sight and multimedia assets. Listening skills are best learned through simple, engaging activities that focus more on the learning process than on the final product. Regardless of whether you are working with a huge gathering of students or a little one, you can utilize any of the accompanying guides to build up your own techniques for showing students how to listen well.

Listening skill/comprehension is an important as well as complex process of language learning. It plays a significant role in second language competence. The process and the act of comprehension are lessened and eased through the context and the purpose. Linguistic knowledge and experiential knowledge are also key ways listeners make use of it to comprehend. There are many tools one can make use of such as computer-assisted language learning [15].

There are several techniques for listening activities developments:

- Interpersonal activities, for example, mock meetings and storytelling. Assign the students to little gatherings of a few, and after that, give them a specific listening activity to achieve.

- Bigger group exercises likewise fill in as a supportive technique for showing listening aptitudes to students.

- You can likewise train listening abilities through sound portions of radio projects, online digital recordings, instructional addresses, and other sound messages.

- Another helpful resource for teaching listening skills is video segments, including short sketches, news programs, documentary films, interview segments, and dramatic and comedic material.

\subsection{Speaking}

Technology can stimulate the playfulness of students and drench them in an assortment of situations. Innovation 
allows students to take part in self-coordinated activities, open doors for self-managed cooperation, protection, and a sheltered situation wherein blunders get redressed and explicit input is given. Input by a machine offers extra an incentive by its capacity to track oversights and connection the understudy quickly to practices that attention on explicit errors. Studies are rising that demonstrate the significance of subjective criticism in programming projects. At the point when connections are given to find clarifications, extra assistance, and reference, the estimation of technology is additionally increased.

Present day technologies accessible in instruction today are:

- Correspondence lab

- Discourse acknowledgment programming

- Interne to technology-enhanced language learning

- Podcasting

- Quick Link Pen

- Quicktionary.

As English today is ranked number one in the worlds in terms of a number of users, the ability to speak fluently has turned into an aptitude of foremost centrality to acquire. An online foreign language speaking class, virtual classes are structured having at the top of the priority list, standards of ELT and e-learning, alongside systems that raise connection, incorporating vocabulary and utilization of English, while giving a calm situation so as to inspire even withdrawn students take an interest and produce spoken language. Use of Oovoo and Skype, Slack, Google Hangout, Trello separated from empowering clients to cooperate with prerecorded messages, additionally give students the choice of synchronous talk, permitting the formation of a virtual class of three to six clients, contingent on the sort of membership - free or paid, respectively. Another advantage given by these two instruments is that students can profit by real learning encounters as opposed to their standard everyday practice, which will thus inspire them to request all the more genuine correspondence subsequently, more opportunities to disguise language [8].

\subsection{Reading}

Online reading perusing is an errand that has all the hallmarks of being important for the $21^{\text {st }}$-century understudies. Along these lines, the production of an Electronic perusing program called "English reading online" was made to limit the hole among perusing and understanding utilizing web-based perusing procedures. The successful utilization of perusing procedures is known to enhance peruser's understanding. As innovation has infiltrated our lives, the impression of perusing for cognizance through innovation needs to transform into a groundbreaking method for doing as such a definitive objective is to empower students to use procedures spontaneously. Notwithstanding, perusing procedures has a few advantages, as well as confinements. For example, the dimension of the members, the study hall settings, and the arrangement of procedures need to be mulled over before connecting with training. Vital perusing guidance benefits all understudies even those of scholastic level. This may be a consequence of lacking secondary school arrangement or little planning amid their time as students. As understudies gain a lot from perusing through procedures which improve their scholastic execution, having it offered through an innovation improved condition increases its impact on understanding while it enables them to figure out how to utilize technology. The assets offered to the understudies through a learning content administration framework called "varsite" enabled them access to a bigger assortment of writings of those found in the college library. This fundamentally gives every understudy the self-rule to get to these assets as per their timetable, empowering them to screen their adapting far and away superior.

\subsection{Writing}

Writing can be perplexing for many students since it requires the correct utilization of language. In contrast to spoken language, composed language cannot utilize motions or non-verbal communication to clarify what it is that should be comprehended or passed on. Played out an investigation where they attempted to recognize the most ideal way an educator can use to show the Latent Voice marvel. They utilized three sorts of classes. The first was "the customary up close and personal way," the second was the "integrative way" where both customary instructing and web-based instructing were utilized, and the third sort was the "online way" where the main sort of educating and materials was electronic What they found was that the coordinated route ended up being the most advantageous for the students, just as that sexual orientation assumes a non-noteworthy job since the outcomes were not unique. It was likewise discovered that the dimension of the understudies changed toward progress after the utilization of the incorporated strategy, in this manner consequences of the post-test essentially varied from the aftereffects of the pretest. This investigation enables us to see that teachers should utilize electronic material as they do improve their students' level utilizing a free and simple to utilize apparatus. The utilization of blog programming and Tweeter are devices that can enable understudies to rehearse composed language, draw in with the language they wish to learn and obviously to share their considerations or emotions 
and think about them [11]. Advancing composition guidance through such an engaging way empowers more generation of composed language which may not have created something else. Students writes blogged instead of going to an in-class session appeared better outcomes from the individuals who just got in-class composing guidance. Instructors should utilize this device as it upgrades composing execution while it is not constrained inside school dividers as it can happen anyplace. The outcome the students who blogged appear to have was an improvement over the individuals who did not, which demonstrates the estimation of the mix of this device. Tweeting likewise is by all accounts a significant device to start the production of network bonds, henceforth permitting the students to discover increasingly about one another also, assemble network bonds. Likewise, while executing gatherings, online journals and wikis in the meantime, this appears to have positive outcomes on understudies' learning progress since this mixed methodology enables them to consider the contrasts which may happen in methods for communicating in English when utilizing composed language.

\section{CONCLUSIONS AND RECOMMENDATIONS}

One of the primary reasons for higher education organizations is to give students the urgent apparatuses to prevail in the worldwide work market. Blended learning has turned out to be a standout among the most well-known approaches to educate EFL because students can find out about various subjects and societies, surf the web and use the technological device they access, for example, iPods, ipads, PCs, Mp3s, and Mp4s, among others. Proficient life is these days heavily relying on mobility and requests experts to exceed expectations in relational abilities at a global, culturally diverse condition. Such activities have multiple benefits, both for the staff who participate and for their schools such as enhanced language skills, innovative teaching methods, and cultural awareness.

The main advantages for students can be

- Social Skills development

- Developing organizational skills

- Learn to use online communication tools

- Does not disturb regular home activities

- Learn how to work as a member of a team of students, international, and/or interdisciplinary

- Develop the skills of self-management and work on a project or proof-of-concept assigned by a company, resulting in real-world, innovative projects

- Experience cultural differences and similarities
- Practice languages other than mother tongue

- Integrated more easily in English language curriculum.

- It provides opportunities to participants with special needs (e.g., online assistance software, medical treatment.,...).

There also some disadvantages such as:

- It is challenges to communicate in a virtual way, especially if not mother tongue

- It is difficult with long-term mobility, but not equivalent

- Cultural communication issues may arise earlier and faster

- Student must have disciplines

- Students need to have a certain level of independence is required

In any case, delicate abilities, just as global presentation, are once in a while tended to college classes. Blended mobility defeats the run of the mill obstructions to mobility, in this way enabling students to exploit the advantages that mobility and worldwide presentation offer. Notwithstanding, paying little respect to its additional esteem, mixed mobility is not really utilized and scarcely perceived as a genuine option with incredible potential to defeat the normal troubles of global mobility.

The blended-aim project sets the basis to support and structure mixed mobility as a rule. In concrete, mixed point enables universal blended-AIM and employability by giving the assets - including preparing, supporting apparatuses and data - to help students and organizations facilitating entrylevel positions and by streamlining inventive instructing ideal models intended to build up students' delicate abilities in a worldwide domain. The framework of blended mobility is a combination of blended learning and mobility learning, which is added to blended learning pedagogy. In general, we hope the higher education in Kurdistan can adapt this system in new bologna process.

\section{REFERENCES}

[1] F. Rizvi. "Global mobility, transnationalism and challenges for education". Transnational Perspectives on Democracy, Citizenship, Human Rights and Peace Education, Bloomsbury Academic, London, p. 27, 2019.

[2] H. Du, Z. Yu, F. Yi, Z. Wang, Q. Han and B. Guo. "Group Mobility Classification and Structure Recognition using Mobile Devices". In: 2016 IEEE International Conference on Pervasive Computing and Communications (PerCom). IEEE, Sydney, pp. 1-9, 2016.

[3] M. T. Batardière, M. Giralt, C. Jeanneau, F. Le-Baron-Earle and V. O'Regan. "Promoting intercultural awareness among European university students via pre-mobility virtual exchanges". Journal of Virtual Exchange, vol. 2, pp.1-6, 2019. 
[4] A. Baroni, M. Dooly, P. G. García, S. Guth, M. Hauck, F. Helm, T. Lewis, A. Mueller-Hartmann, R. O'Dowd, B. Rienties and J. Rogaten. "Evaluating the impact of virtual exchange on initial teacher education: A European policy experiment". Researchpublishing. net, Voillans, France, 2019.

[5] T. Andersen, A. Jain, N. Salzman, D. Winiecki and C. Siebert. "The Hatchery: An Agile and Effective Curricular Innovation for Transforming Undergraduate Education". In: Proceedings of the 52 $2^{\text {nd }}$ Hawaii International Conference on System Sciences, 2019.

[6] J. O'Donnell and L. Fortune. "Mobility as the teacher: Experience based learning. In: The Study of Food, Tourism, Hospitality and Events". Springer, Singapore, pp. 121-132, 2019.

[7] C. J. Bonk and C. R. Graham. "The Handbook of Blended Learning: Global Perspectives, Local Designs". John Wiley and Sons, Hoboken, 2012.

[8] J. MacDonald. "Blended Learning and Online Tutoring: A Good Practice Guide". Gower, UK, 2006.

[9] I. Falconer and A. Littlejohn. "Designing for blended learning, sharing and reuse". Journal of Further and Higher Education, vol. 31, no. 1, pp. 41-52, 2007.

[10] M. I. Ghareb and S. A. Mohammed. "The effect of e-learning and the role of new technology at university of human development". International Journal of Multidisciplinary and Current Research, vol. 4, pp. 299-307, 2016.

[11] M. I. Ghareb and S. A. Mohammed. "The role of e-learning in producing independent students with critical thinking". International Journal of Engineering and Computer Science, vol. 4, no. 12, pp. 15287, 2016.

[12] P. Neumeier. "A closer look at blended learning parameters for designing a blended learning environment for language teaching and learning". ReCALL, vol. 17, no. 2, pp.163-178, 2005.

[13] D. Dozier. "Interactivity, Social Constructivism, and Satisfaction with Distance Learning Among Infantry Soldiers". (Doctoral Dissertation), 2004.

[14] M. I. Ghareb, S. H. Karim, Z. A. Ahmed and J. Kakbra. "Understanding student's learning and e-learning style before university enrollment: A case study in five high schools/sulaimaniKRG”. Kurdistan Journal of Applied Research, vol. 2, no. 3, pp. 161-166, 2017.

[15] M. I. Ghareb and S. A. Mohammed. "The future of technologybased classroom". UHD Journal of Science and Technology, vol. 1, no. 1, pp. 27-32, 2017.

[16] F. Mortera-Gutiérrez. "Faculty best practices using blended learning in e-learning and face-to-face instruction". International Journal on E-learning, vol. 5, no. 3, pp.313-337, 2006.

[17] M. I. Ghareb, Z. A. Ahmed and A. A. Ameen. "The role of learning through social network in higher education in KRG". International Journal of Scientific and Technology Research, vol. 7, no. 5, pp. 20-27, 2018.

[18] M. P. Menchaca and T. A. Bekele. "Learner and instructor identified success factors in distance education". Distance education, vol. 29, no. 3, pp. 231-252, 2008.

[19] S. Wichadee. "Facilitating students' learning with hybrid instruction: A comparison among four learning styles". Electronic Journal of
Research in Educational Psychology, vol. 11, no. 1, pp. 99-116, 2013.

[20] J. A. Lencastre and C. P. Coutinho. Blended learning. In: "Encyclopedia of Information Science and Technology". $3^{\text {rd }}$ ed. IGI Global, Hershey PA, pp. 1360-1368, 2015.

[21] M. Macedo-Rouet, M. Ney, S. Charles and G. Lallich-Boidin. "Students' performance and satisfaction with Web vs. paper-based practice quizzes and lecture notes". Computers and Education, vol. 53, no. 2, pp. 375-384, 2009.

[22] D. Neubersch, H. Held and A. Otto. "Operationalizing climate targets under learning: An application of cost-risk analysis". Climatic Change, vol. 126, no. (3-4), pp. 305-318, 2014.

[23] N. Deutsch and N. Deutsch. "Instructor Experiences with Implementing Technology in Blended Learning Courses". ProQuest, UMI Dissertation Publishing, 2010.

[24] P. Mitchell and P. Forer. "Blended learning: The perceptions of first-year geography students". Journal of Geography in Higher Education, vol. 34, no. 1, pp. 77-89, 2010.

[25] R. B. Marks, S. D. Sibley and J. B. Arbaugh. "A structural equation model of predictors for effective online learning". Journal of Management Education, vol. 29, no. 4, pp. 531-563, 2005.

[26] C. W. Holsapple and A. L. Post. "Defining, assessing, and promoting e learning success: An information systems perspective". Decision Sciences Journal of Innovative Education, vol. 4, no. 1, pp. 67-85, 2006.

[27] C. Greenhow, B. Robelia and J. E. Hughes. "Learning, teaching, and scholarship in a digital age: Web 2.0 and classroom research: What path should we take now"? Educational Researcher, vol. 38, no. 4, pp. 246-259, 2009.

[28] M. V. López-Pérez, M. C. Pérez-López and L. Rodríguez-Ariza. "Blended learning in higher education: Students' perceptions and their relation to outcomes". Computers and Education, vol. 56, no. 3, pp. 818-826, 2011.

[29] B. H. Khan, editor. "Managing e-learning: Design, Delivery, Implementation, and Evaluation". IGI Global, Hershey PA, 2005.

[30] B. Wächter and S. Wuttig. "Student Mobility in European Programmes". EURODATA: Student Mobility in European Higher Education, pp.162-181, 2006.

[31] B. Schreurs, S. Verjans and W. Van Petegem. "Towards Sustainable Virtual Mobility in Higher Education Institutions". In: EADTU Annual Conference, 2006.

[32] H. De Wit. "Global: Internationalization of Higher Education: Nine Misconceptions". In: Understanding Higher Education Internationalization. Sense Publishers, Rotterdam, pp. 9-12. 2017.

[33] K. Thompson, R. Jowallah and T. B. Cavanagh. "Solve the Big Problems: Leading Through Strategic Innovation in Blended Teaching and Learning". In: Technology Leadership for Innovation in Higher Education. IGI Global, Hershey PA, pp. 26-48, 2019.

[34] S. Adam. "Learning Outcomes Current Developments in Europe: Update on the Issues and Applications of Learning Outcomes Associated with the Bologna Process". In: Presented to the Bologna Seminar: Learning Outcomes Based Higher Education: The Scottish Experience, Edinburgh: Scottish Government, 2008. 